\title{
Ministrar uma Oficina Remota em tempos de pandemia: uma experiência vivida por duas docentes humanistas dos cursos de Licenciatura em Letras da UFRRJ
}

\author{
Ministrar un Taller Remoto en tiempos de pandemia: una experiencia vivida por dos docentes humanistas de \\ los cursos de Licenciatura en Letras de la UFRRJ
}

\author{
Debora Ribeiro Lopes Zoletti \\ Universidade Federal Rural do Rio de Janeiro - UFRRJ - Rio de Janeiro - Brasil
}

Maristela da Silva Pinto

Universidade Federal Rural do Rio de Janeiro - UFRRJ - Rio de Janeiro - Brasil

\begin{abstract}
Resumo: A crise sanitária causada pela COVID19, que se instalou no mundo em inícios de 2020, significou a real e urgente necessidade de busca por novos caminhos, adaptando métodos e teorias, a fim de que o processo educacional formal, apesar do fechamento das instituições, tanto no nível de educação básica quanto no superior, pudesse ter continuidade. Diante desse cenário, como fazer funcionar a prática de uma educação humanista (Freire, 1996; Pacheco, 2014; Aloni, 2011; Leite, 2015) sem o espaço físico potencializador das relações humanas e, portanto, sem o contato físico entre os sujeitos da aprendizagem? O desafio estava posto. A insegurança e os medos que o momento vivido denotavam, não foram obstáculos suficientes para que professores, pais e estudantes paralisassem diante das demandas que o "novo normal" nos exigia. Todos fomos convocados a nos reinventarmos. $E$, atendendo a tal convocação, duas professoras universitárias, de essência e práticas humanistas e que prezam pela construção social e coletiva do conhecimento, se adaptaram, planejaram e colocaram em prática, na modalidade remota, a oficina "Propostas didáticopedagógicas em Espanhol como LE: domínios linguístico, social e cognitivo e o gênero ficcional, sob o olhar de uma abordagem humanista", com carga horária total de 30 horas e destinada aos estudantes dos Cursos de Licenciatura em LetrasEspanhol/Literaturas da UFRRJ. O presente artigo tratará dessa experiência, desde seu planejamento, passando pelo seu desenvolvimento e culminando na avaliação crítica acerca do processo. Além disso, também serão explicitados os conteúdos teóricos e práticos que fundamentam o objetivo da oficina: atualizar os licenciandos, futuros professores de língua espanhola e ou portuguesa e suas respectivas literaturas, dentro de uma perspectiva didático-metodológica consolidada pelo trato equânime dos domínios lingüístico, social e cognitivo, somados à abordagem humanista da educação.
\end{abstract}

Palavras-chave: Pandemia; Educação humanista; Espanhol como LE.

Abstract: La crisis sanitaria debido a la Covid19 que se instaló en el mundo en inicios de 2020, significó la real y urgente necesidad de búsqueda por nuevos caminos, con adaptación de métodos y teorías a fin de que el proceso educacional formal, a pesar del cierre de las instituciones de enseñanza básica y superior, siguiese. Delante de este panorama, ¿cómo poner en práctica la educación humanista (Freire, 1996; Pacheco, 2014; Aloni, 2011; Leite, 2015) con la ausencia del espacio físico propicio a las relaciones humanas y, por lo tanto, desproveído de contacto físico entre los sujetos del aprendizaje? El desafío estaba puesto. La incertidumbre y los miedos que el momento denotaban, no se configuraron como obstáculos suficientes para que profesores, familias y estudiantes se detuviesen delante de las demandas que la "nueva normalidad" nos exigía. Todos hemos sido convocados a una reinvención de nosotros mismos. Como respuesta activa a esta convocación, dos profesoras universitarias, de esencia y prácticas humanistas, y que defienden la construcción social y colectiva del conocimiento, se adaptaron, planearon y pusieron en marcha, en la modalidad remota, el taller "Propostas didático-pedagógicas em Espanhol como LE: domínios linguístico, social e cognitivo e o gênero ficcional, sob o olhar de uma abordagem humanista", con carga horaria total de 30 horas, destinado a los estudiantes de los Cursos de Licenciatura en Letras-Español/Literaturas de UFRRJ. Este artículo tratará de dicha experiencia, desde su planificación, su desarrollo y culminará con la discusión acerca de la evaluación crítica del proceso. Además, también serán explicitados los contenidos teóricos y prácticos que fundamentan el objetivo del taller: actualizar a los licenciandos, futuros profesores de lengua española y o portuguesa y sus respectivas literaturas, 
según una perspectiva didáctico metodológica consolidada por el trato equitativo de los dominios lingüístico', social y cognitivo, además del abordaje humanista de la educación.

Resumen : Pandemia, educación humanista, Español como LE

\section{Do choque à ação}

Em março de 2020 nossas realidades de vida pessoal e profissional sofreram uma repentina, intensa e drástica mudança. Um vírus - o novo Corona vírus que pelo que se sabe até o presente momento, surgiu na China e fez grande estrago por lá, se alastrou rapidamente alcançando os demais continentes e chegou em nossas terras brasileiras. Nos primeiros meses pandêmicos, segundo dados do Banco Mundial , mais de 1,5 bilhões de jovens, distribuídos em 174 países, ficaram fora da escola em cumprimento das orientações determinadas pela Organização Mundial de Saúde (OMS). No Brasil, todas as escolas e universidades tiveram suas atividades suspensas e foram fechadas por tempo indeterminado. Estava decretado o isolamento social. Se tal decreto fora cumprido à risca ou não, não será foco de discussão nesse trabalho.

Em pleno início de semestre letivo, ficamos "parados", apreensivos, amedrontados, porém confiantes de que esse "paro"/"stop", seria apenas uma medida cautelosa com duração de cerca de 15 dias. Em pouco tempo nossas ingênuas e esperançosas estimativas subiram de 15 para 30 dias. Não muito tempo depois, nos demos conta de que se tratava de algo muito acima daquilo que desejávamos e imaginávamos. Estávamos todos diante de uma crise sem precedentes e de proporção global, perante a qual, famílias e educadores, lidando com a imprevisibilidade e em benefício da vida, precisariam, respectivamente, reconstituir suas dinâmicas domésticas e reaprender outras formas de ensinar.

Foi assim que nossa instituição de ensino superior, a UFRRJ, estabeleceu um Plano de Trabalho Remoto, no qual seus docentes deveriam descrever todo o trabalho que desenvolveriam remotamente nos âmbitos da extensão, da administração e da pesquisa. Levando em consideração o pensamento do educador português José Pacheco (2019) de que "escolas não são prédios; escolas são pessoas aprendendo na intersubjetividade, isto é, umas com as outras, numa relação mediada pelo mundo", nos lançamos ao desafio de criarmos, com os recursos digitais que dispúnhamos, condições de se estabelecer esse tipo de aprendizagem, ainda que virtualmente. Se escolas "não são prédios", porque não lançar mão daquilo que já há muito tempo faz parte de nossa realidade - a tecnologia - com o intento de minimizar perdas que o isolamento trouxe no âmbito do ensino presencial? Se, no dia a dia, jovens usam e abusam do mundo virtual para entretenimento e interação social, por que não apostar nesse "espaço cibernético" para a construção do conhecimento também de forma interativa e subjetiva? Embora separados pela tela do computador/telefone/tablet, o momento emergencial vivido nos apontou para uma possibilidade que, planejada adequadamente e adaptada quando necessário, se mostrou viável e possível.

A fim de consolidar o trabalho remoto no âmbito da extensão universitária, a Pró-reitoria de Extensão (PROEXT/UFRRJ) lançou edital para que os professores pudessem ofertar cursos para a comunidade e/ou para os estudantes de graduação com o objetivo de manter um vínculo com a comunidade acadêmica e, também, de dar continuidade as nossas produções acadêmicas ao longo do período da pandemia. Debruçamo-nos nesse edital, idealizamos, elaboramos e submetemos uma proposta de oficina remota à Escola de Extensão (Eext). Uma vez aceita, a divulgamos e a efetuamos. Nossa oficina remota, intitulada "Propostas didáticopedagógicas em Espanhol como LE: domínios linguístico, social e cognitivo e o gênero ficcional, sob o olhar de uma abordagem humanista", aconteceu de maio a julho de 2020, contava com um encontro semanal e um total de 30 horas.

\section{Todo caminho novo amedronta, porém nos impulsiona a não permanecer inertes.}


Adaptar nossa proposta de oficina presencial para a modalidade remota nos gerou certa insegurança. Titubeamos por algum tempo. As incertezas de modo geral e o receio quanto à aceitação e ao número de interessados em se inscrever na oficina pesava em nossa decisão enquanto proponentes. Também nos preocupávamos diante das incertezas quanto a nossa capacidade de dar conta ou não das ferramentas, (principalmente por estarmos vivendo situações no ambiente doméstico com condições bastante diferenciadas daquilo que consideramos como nossa "normalidade"). Dúvidas do tipo: "que plataforma usar?" "Seriam encontros assíncronos e síncronos?" "Faremos encontros on-line ou só trabalho de leitura de bibliografia indicada?" "Seria possível a ocorrência de interação ainda que não houvesse conexão ao vivo?" Enfim, havia muito mais perguntas do que respostas, o que é normal diante desse cenário tão novo e incerto, mas que vemos como algo positivo porque nos impulsiona a seguir em frente, vencendo qualquer barreira imposta pelo medo. Nossa primeira insegurança foi resolvida: houve inscritos. Abrimos poucas vagas e diante da rápida lotação abrimos vagas extras as quais também foram ocupadas. Parecia que estava tudo caminhando a contento. Com relação às ferramentas, optamos em usar o próprio programa da instituição, pois nós, docentes, e discentes o dominávamos minimamente. Mas como desejávamos estabelecer algum tipo de interação entre nós e os participantes, exploramos mais a fundo a plataforma institucional SIGAA/UFRRJ - e descobrimos que a possibilidade de se criar "Comunidade Virtual" se mostrou como uma ferramenta bem mais completa do que supúnhamos. Exploramos significativamente os recursos "tópicos" e "fórum" dentro da nova "Comunidade Virtual" criada para nossa oficina. No "tópico" disponibilizávamos as apresentações idealizadas e elaboradas por nós com os devidos conteúdos e referencias de leituras extras. Os "oficineiros" as acessavam e faziam o que estava proposto como aprofundamento teórico de cada encontro. No recurso "fórum", estabelecíamos a interação entre nós e os participantes da oficina. Após cada encontro, eles tinham uma semana para realizar as tarefas sugeridas e/ou ler a bibliografia indicada e, posteriormente, analisar o que os colegas "oficineiros" haviam feito e escolher um para elaborar um comentário e uma réplica ao comentário. Toda a dinâmica (leituras, elaboração, análise, comentários e réplicas) para realização plena das atividades da oficina estava explicada detalhadamente já na própria tela de início da "Comunidade Virtual" da plataforma SIGAA. (figura 1).

Figura 1: Print da página inicial de nossa comunidade virtual

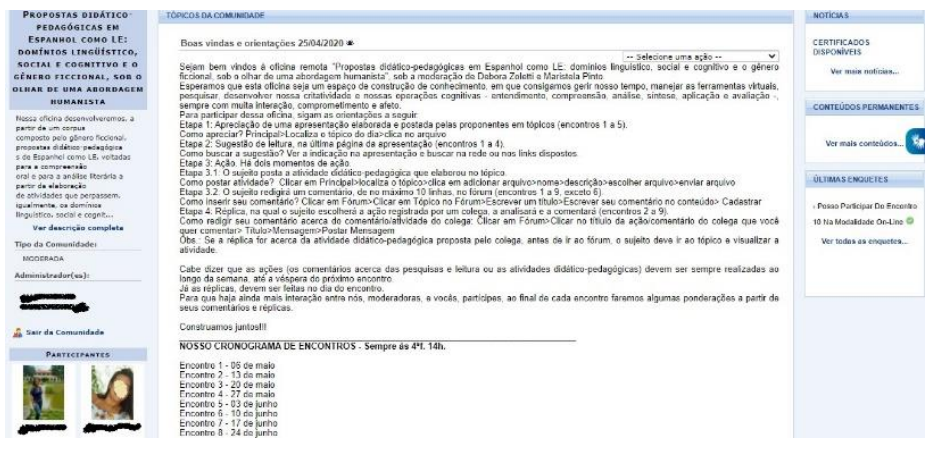

Sobre a possibilidade dos encontros serem de forma assíncrona ou síncrona, a condição instável da conexão de internet, devido ao congestionamento de usuários não só na mesma casa, mas também nos arredores, nos levou a optarmos por encontros assíncronos a fim de minimizar algumas das dificuldades que os partícipes pudessem ter com relação ao uso dos recursos digitais.

Em nossa prática, a cada encontro marcado de acordo com o cronograma estabelecido, postávamos uma apresentação teórico-conceitual e, ao final desta, indicações bibliográficas sobre o tema e uma tarefa a ser realizada. Durante a semana os sujeitos-aprendizes "oficineiros" liam os textos, cumpriam e postavam sua tarefa. No dia do novo encontro, liam a tarefa dos colegas, comentavam-na e havia a possibilidade de réplica. Ao final do dia, nós, as proponentes da oficina, líamos uma a uma as tarefas e os comentários/réplicas realizados e fazíamos ponderações. Foi essa a maneira que encontramos a fim de estabelecer uma real (embora virtual) interação entre eles e entre eles e nós. Desta forma, sentiam-se acolhidos e amparados apesar do distanciamento físico. Além disso, disponibilizamos 
nossos e-mails para eventuais perguntas, o que também configurou como momentos interativos.

\section{Nossa Oficina Remota na concretude}

Nossos objetivos ao idealizar essa oficina remota eram, além de "fugirmos" (todos nós, professores e estudantes) da realidade dolorida que 0 isolamento nos causava, fazer com que nossos estudantes deslocassem seus pensamentos e energias em torno do tema Covid-19 e se voltassem na direção do "respirar outros ares". Além disso, objetivávamos ainda dar continuidade ao repensar e ao transformar o processo educacional e de formação, mesmo diante daquele cenário sombrio. Esperávamos que, ao longo do processo, os participantes repensassem o papel fundamental da escola no século $\mathrm{XXI}$; construíssem um novo olhar a respeito do ensino de Espanhol como LE nessa escola do século XXI e desenvolvessem sua criatividade e consciência crítica para o trabalho de elaboração de atividades didáticopedagógicas.

Desse modo, nos propusemos a partilhar com eles uma práxis de ensino-aprendizagem de língua estrangeira que idealizamos, desenvolvemos, aplicamos e acreditamos ser eficiente para a construção de uma escola com corpo e alma e, assim, instrumentalizá-los para que possam incorporá-la em sua atuação pedagógica. Uma vez o objetivo definido, nossos "oficineiros" realizaram a oficina tendo em vista a seguinte divisão (de acordo com o cronograma de horas estabelecido):

Encontro 1 - Tema: Repensando a escola do século XXI. Neste encontro, apresentamos aos "oficineiros" o fundamento de nossa proposta humanista para o ensino de Espanhol como Língua Estrangeira. Nele, mostramos que a escola do século $\mathrm{XXI}$, além de explorar o conteúdo curricular adequado ao nível em que se atua, deve também trabalhar com foco na dinâmica das relações sociais, explorando e desenvolvendo em seus sujeitos-aprendizes as diferentes operações cognitivas (as quais se mostram imprescindíveis na solução dos problemas diários, dos mais simples aos mais complexos) e, somado a isso, que os constituam em sujeitos capazes de usar todo o conhecimento construído e partilhado de forma prudente e responsável em sua vivência.

Encontro 02 - Tema: Apresentação dos domínios - linguístico, social e cognitivo. Neste encontro os "oficineiros" tiveram a oportunidade de se aprofundarem teoricamente em cada um dos domínios tratados a partir dos estudos de Hodges e Nobre (2012), as quais defendem que a prática educativa deve estar pautada em atividades pedagógicas que perpassem, igualmente, os "domínios linguístico, social e cognitivo"

Encontro 03 - Tema: Apresentação da abordagem humanista. Neste encontro apresentamos a nossos "oficineiros" os fundamentos básicos da abordagem humanista. Para tal, lançamos mão dos estudos de Aloni (2011), Leite (2015), Mattos (2011), Pacheco (2014), que defendem que a educação não pode ser apenas conteudista, mas sim, e, principalmente, humanista. Uma educação humanista está pautada em ações direcionadas pela ética, pela criatividade e pela responsabilidade social. Trata-se, portanto de uma educação que, podendo partir de projetos integrados às diversas áreas, promova não só a construção do conhecimento técnico, mas também, e principalmente, a consolidação de inter-relação entre os sujeitosaprendizes e entre eles e o mundo a seu redor, de forma a humanizar (ou a re-humanizar) a sua formação tanto no âmbito pessoal, quanto no profissional.

Encontro 04 - Tema: Apresentação do domínio ficcional. Nesse encontro, retomamos as reflexões acerca dos variados gêneros textuais com base nos estudos de Marcuschi (2008), em especial, os do domínio ficcional.

Encontro 05 - Tema: Exemplificação de uma proposta didático-pedagógica que perpasse os três domínios em uma abordagem humanística a partir do gênero história em quadrinhos. Neste encontro, apresentamos aos "oficineiros" um exemplo de proposta didático-metodológica correspondente a nossa metodologia de exploração domínios somada à abordagem humanista. Para tal, disponibilizamos um texto (gênero: quadrinho - figura 2) e explicitamos um 
possível caminho para elaboração de uma atividade pautada nos domínios e na abordagem humanista.

Figura 2: Texto-base utilizado em nossa atividade de apresentação da metodologia proposta

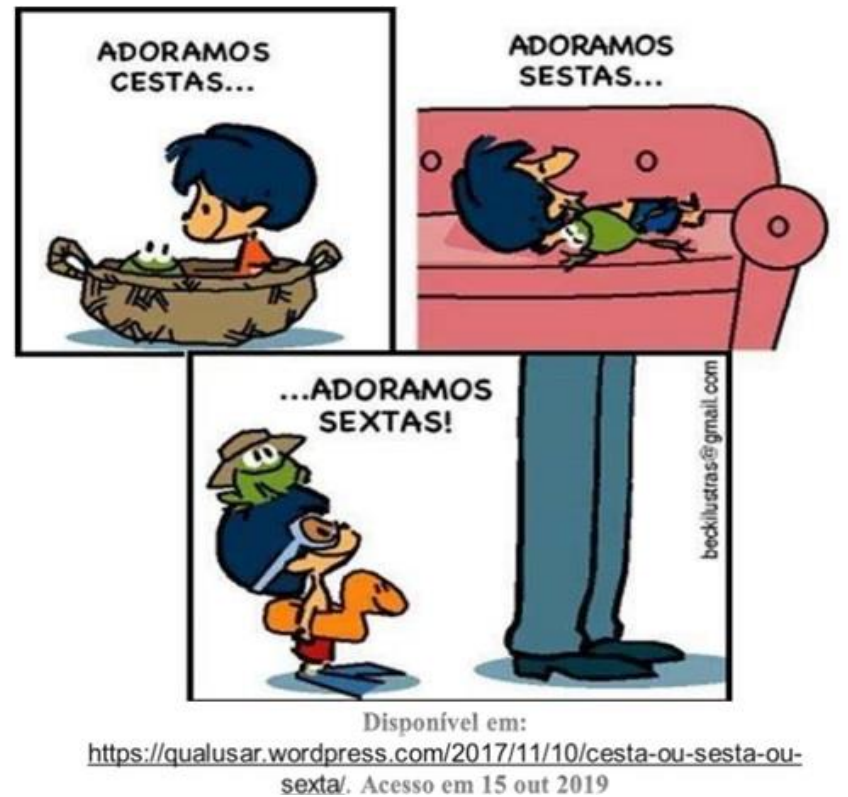

A partir do quadrinho selecionado, desenvolvemos a seguinte proposta a ser solidificada em uma atividade didático-pedagógica: pensando no domínio linguístico (DL), podemos abordar o signo linguístico - significante e significado. Embora as três "cestas, sestas e sextas" tenham os mesmo significantes - sons - apresentam significados distintos. No que concerne ao domínio cognitivo (DC) focamos na compreensão, tendo de examinar os vocábulos descritos e identificar que, embora apresentem os mesmos significantes, têm significados distintos. No que se refere ao domínio social (DS), levamos à reflexão de que cada situação comunicativa pede um vocábulo específico, mas as pessoas podem se equivocar na escrita destes porque, muitas vezes, estes vocábulos apresentam o mesmo significante. Focando na abordagem humanista $(\mathrm{AH})$, indicamos que o que vale é usar o conhecimento de forma prudente e responsável, desse modo, não ter preconceito com o outro que se equivoca na escrita e sim tentar entender o que o levou a cometer tal "equívoco", no caso em questão, o fato de apresentarem os mesmos significantes.

\section{Encontro 06 - Tema: Trabalhando o gênero} canção. Propor um item na atividade didático pedagógica nesse formato. Neste encontro, pedimos que os "oficineiros" elaborassem um item tendo a música "Calma" (gênero canção) como texto-base, a partir do seguinte exemplo que elaboramos:

En la canción de Pedro Capó, hay una invitación a su interlocutor (-a) que se evidencia en los versos "Vamos pa' la playa. $\mathrm{Pa}$ ' curarte el alma. Cierra la pantalla" (DS). Tras oír esos versos, identifica (DC) si el hablante/cantante es distinguidor o yeísta (DL). Tras eso, compara (DC) el habla de ese cantante con otros cantantes hispanos y di si todos los hablantes hispanos hablan como él (DL). Diserta (DC) sobre. (DL - DS). En tu vida, ¿cómo debes portarte cerca de alguien que tiene un acento distinto del tuyo? (AH).

Encontro 07 - Tema: Trabalhando o gênero poema. Propor um item de atividade didático pedagógica nesse formato. Neste encontro, pedimos aos "oficineiros" que elaborassem um item tendo o texto literário "La mosca que soñaba en ser un águila" (gênero poema) como texto-base, a partir do seguinte exemplo que elaboramos:

Las fábulas son textos literarios que cumplen una función didáctica importante al exponer o criticar aspectos de la sociedad en general (DS). Busca (DC) en el texto "la mosca que soñaba ser un águila" los recursos estilísticos/literarios que caracterizan una fábula (DL). Luego, relaciona (DC) el uso de dichos recursos al significado (DL) de la crítica social implícita (DS) que se consolida en la fábula seleccionada. Por fin, evalúa (DC) la inquietud de la mosca y apunta (DC) un consejo que le darías si fueras tú una mosca también. $(\mathrm{AH})$

\section{Encontro 08 - Tema: Trabalhando diversos} gêneros do domínio ficcional. Escolher um dos gêneros do domínio ficcional, selecionar o texto e elaborar uma proposta didático-metodológica completa no formato indicado pela Oficina. Neste encontro o objetivo era que cada um dos "oficineiros" elaborassem uma proposta completa de atividade didático-pedagógica. Assim, pedimos a eles que elaborassem uma atividade dividida em "pré-leitura", "leitura" e "pós-leitura", tendo como texto-base um poema, fábula, lenda, $\mathrm{HQ}$ ou crônica do universo hispânico.

\section{Encontro 09 - Avaliação da oficina e} autoavaliação do estudante. Acreditamos ser de extrema importância utilizar a ferramenta "avaliação" como estratégia pedagógica e não, apenas, como instrumento de verificação da aprendizagem (Caldeira, 2004). Isto é, para nós, uma avaliação funciona 
também como uma busca por formas de preencher possíveis lacunas ao longo do processo de construção do conhecimento pelo estudante, em nosso caso, pelos "oficineiros". Além dessa ferramenta, também exploramos em nossa oficina a ferramenta de "Autoavaliação", visto que ela funciona para o estudante como uma estratégia de reflexão sobre o próprio desempenho, facilitando assim, tanto para estudante e quanto para professor, a identificação e correção de possíveis falhas ao longo do processo formativo. Assim, tendo como objetivo receber um feedback do trabalho realizado durante 0 desenvolvimento da oficina remota, pedimos aos "oficineiros" que a avaliassem e os autoavaliassem a partir dos seguintes critérios:

\section{Avaliação da oficina (de 1 a 5 estrelas) \\ Organização}

Embasamento teórico indicado

Proposta da oficina

Clareza nos comandos

Interação com as proponentes

Expectativa condizente com a realidade da oficina

Ferramenta adotada para o desenvolvimento da oficina na modalidade remota

Duração da oficina

\section{Autoavaliação na oficina (de 1 a 5 estrelas) Assiduidade \\ Dedicação \\ Interesse \\ Partilha com os demais nas réplicas \\ Motivação}

\section{Encontro 10 - Tema: Considerações finais}

da Oficina Remota. Neste encontro nos propusemos a dividir com nossos "oficineiros" nossa percepção acadêmica, mas também, e principalmente, humana diante daquela experiência tão desafiante quanto nova para todos nós. Foi o momento em que fizemos uma retrospectiva de todo o processo, desde sua idealização até o 10ํe encontro. Deixamos registrados dois sinceros depoimentos, de duas professoras essencialmente humanistas dentro e fora do universo acadêmico, isto é, na vida:

Depoimento 01: "Sem dúvida, realizar essa oficina remota foi um grande desafio para nós, docentes e discentes, afinal não estamos vivendo o melhor ano de nossas vidas, há um caos lá fora, medo, dúvidas, ansiedade, mas também há muita vontade de se manter são, de se sentir vivo, de produzir, de aprender, de fazer valer à pena. Pensando em manter o vínculo com a academia e em ser "útil" para a educação, nos lançamos nessa aventura. Agradecemos, imensamente, a todos que se inscreveram, aos que puderam participar de alguns encontros e, em especial, agradecemos àqueles que seguiram firmes até este último encontro. Sabemos que não foi fácil, sabemos que os que desistiram tiveram seus motivos e a vocês que permaneceram, nosso muito obrigada. Foi um modelo novo para todos nós e nossa maior preocupação era, "será que entenderão os comandos, será que haverá interação?" "Porque o que é a educação se não uma troca de experiências?" E para nossa felicidade, a resposta foi "sim". As interações, que julgamos tão importantes, estiveram presentes a partir do olhar crítico construtivo acerca do comentário e/ou atividade do colega, sempre com muito respeito e criticidade. Temos certeza de que muito se aprende com essa interação, com essa troca. Que vocês a levem para a vida."

Depoimento 02: "Escrevo como forma de ratificação da fala anterior. Uma fala de quem é minha parceira de vida e de profissão. E já que comecei falando em parceria, digo para vocês, de coração, a satisfação e felicidade que foi tê-los como parceiros nessa oficina. A essência da educação humanista está aí, no compartilhamento e na construção coletiva do conhecimento. Perceberam o quanto todos nós crescemos juntos nesse processo? Apesar das dificuldades que o atual momento nos impôs, julgamos ter alcançado o objetivo central de nossa oficina. Não sabíamos onde "estávamos pisando", principalmente, no que se refere à modalidade remota de ensino, mas, juntas nos desafiamos a essa nova experiência e, com a também parceria de vocês, conseguimos, com louvor, unir nossas forças e desejos em prol daquilo que acreditamos e defendemos. Sim, foi, no mínimo, "estranho" não estarmos juntos fisicamente. Mas, como seres adaptáveis que somos, tentamos ao máximo, nos aproximarmos fazendo o bom uso da tecnologia da qual dispomos. Por mais que sintamos muitaaaaa falta do contato físico, das trocas presencias, acreditamos que o saldo foi bastante positivo. Não estávamos juntos fisicamente, mas virtualmente sim. Sentíamos vocês em cada interação virtual e isso significou, de certa forma, um alento para nós, professoras que amamos vivenciar os espaços formativos concretos. De novo: obrigada! De novo: esperamos que vocês incorporem na vida (profissional e pessoal) o que viveram nessa experiência! Ficaremos ainda mais felizes e orgulhosas! Por fim, antes de "falar" diretamente a cada um dos "oficineiros", ficamos na esperança de que, em breve, possamos voltar às trocas presenciais."

\section{Nosso olhar autocrítico: fracassos e} êxitos

Avaliando o processo como um todo, acreditamos que, apesar de todas as dificuldades impostas pelo cenário pandêmico, nos deparamos com maiores indícios de êxito do que de fracasso.

O ponto que julgamos como "fracasso" equivale ao baixo quantitativo de "oficineiros" que puderam concluir nossa oficina remota. Buscamos, ao longo do processo, saber o motivo de tal desistência e 
percebemos que suas causas estavam muito mais diretamente relacionadas ao momento adverso que vivíamos do que às questões relacionadas à proposta da oficina remota. Para alguns inscritos a não conclusão da oficina se deu porque contraíram a COVID-19 ao longo de sua realização. Outros tiveram familiares que a contraíram e até faleceram. E outros porque não conseguiram, embora desejassem, conciliar a alterada dinâmica da vida doméstica à dedicação que a oficina minimamente exigia de seus participantes. Houve também aqueles que, por questões psíquico-sociais geradas pelo momento, encontraram dificuldade para concluir a oficina. E por fim, segundo nosso diagnóstico, houve também aqueles inscritos que não se atentaram à necessidade do conhecimento da Língua Espanhola sinalizada no momento da inscrição e, portanto, não apresentavam condições acadêmicas de concluir a oficina.

Já como pontos de êxito, destacamos muitos. Os poucos que permaneceram, cresceram muito ao longo da oficina. Foi claramente perceptível o quanto os participantes foram numa crescente dentro daquilo que estávamos propondo. O fazer da primeira tarefa ao fazer da última indica que, de fato, os "oficineiros" compreenderam plenamente nossa proposta de ensino, exercitando-a, aperfeiçoando-a até sua aplicação na prática. Os mesmos relataram que passaram a ver a educação de outra forma e que pretendem ajustar suas práticas pedagógicas voltadas para essa nova práxis formativa. E por fim, algo que também nos deixou extremamente satisfeitas, foram os depoimentos dos participantes quanto à percepção de sua mudança interior. Relataram que seu olhar para o mundo ficou mais humano e que a oficina se converteu em um momento de alento no meio ao caos. Enfim, acreditamos que os objetivos de nossa oficina não só foram alcançados, como também nos trouxeram, em forma de uma grata surpresa, uma imensa satisfação por percebermos que, embora diante das novas condições desfavoráveis e desafiadoras advindas com a pandemia no campo da educação, foi possível, a partir de um trabalho em conjunto, vivenciar alguns dos aspectos preconizados pela educação humanista: fortalecer o ambiente formativo, seja de forma presencial ou virtual, como uma comunidade de aprendizagem (José Pacheco, 2019), construída por sujeitos que interagem num espaço de relação humana, repleto de afeto, vínculo e socialização.

\section{Considerações finais}

Sim, tivemos medo. A cada novo dia pandêmico, vivíamos momentos de "tensa expectativa, de alguma ambiguidade, de apreensão, mas também de teimosa confiança". Apesar de todo o cenário apreensivo, tumultuado e incerto, a satisfação e a felicidade que se instauraram em nós, ao longo do processo, foram o reflexo do êxito da experiência vivida. Como "pombas com ramos de oliveira atravessados nos bicos" nos lançamos ao novo vôo e, mesmo diante de subjetivas barreiras, "o medo não era sentimento que se cultivasse" pela simples razão de que não se tratava de um vôo solo. Tínhamos uma à outra e aos nossos "oficineiros" que, como "pássaros aprendizes", todos juntos, sedentos em construir novos ninhos, voamos e nos sentimos como José Pacheco, muito poeticamente, expressou em uma de suas cartas diárias: “(...) Hoje, sinto-me quase feliz, à beira de voar sonhos novos. Medo não sinto. $E$ até $o$ inesperado me fascina. É um sentimento forte e, ao mesmo tempo, leve e doce. Medo não sinto, porque não parto sozinho." (PACHECO, 2020) .

A Oficina Remota "Propostas didáticopedagógicas em Espanhol como LE: domínios linguístico, social e cognitivo e o gênero ficcional, sob o olhar de uma abordagem humanista" foi nossa primeira experiência no ensino remoto. Não passamos por nenhum tipo de capacitação e não tínhamos experiência, mas carregávamos dentro de nós muita gana de fazer dar certo. Instigadas por essa vontade, fomos entendendo e descobrindo a ferramenta digital disponível e, ao final do processo, podemos afirmar, com segurança, que deu certo. Não poderíamos deixar de sinalizar os agentes fundamentais para que 0 resultado final tenha sido esse: 0 belo trabalho desenvolvido por cada um dos "oficineiros". Indubitavelmente eles entenderam nossa proposta e, 
mais do que na teoria, conseguiram concretizá-la, na prática, com suas atividades didático-metodológicas que vieram em uma crescente significativa. Julgamos que o tempo destinado à duração da oficina foi a contento, pois o calculamos de forma a contemplar um espaço para as leituras, para digerir e concretizar a tarefa proposta e outro espaço para colocá-la em prática. Sentimos falta de um encontro síncrono (live), porque consideramos o contato interpessoal imprescindível, mas a interação, o diálogo, o feedback estiveram presentes todo o tempo. A princípio não estávamos certas acerca de dar ou não um retorno (o nosso feedback) encontro a encontro mas, com a oficina acontecendo, percebemos que este era imprescindível. Foi nossa forma de dizer a nossos "oficineiros" "Continuem! Estamos aqui para o que precisarem, não é só uma tela, há duas profissionais da educação aqui junto de vocês e muito gratas por vocês estarem do outro lado da tela com a gente!".

\section{REFERÊNCIAS}

ALONI, Nimrod. Educação Humanística. Tradução: Silvia Moreira Leite. Disponível em: $<$ chrome-

extension://oemmndcbldboiebfnladdacbdfmadadm/htt ps://www2.unifap.br/borges/files/2011/02/Educa\%c3\% a7\%c3\%a3o-Human\%c3\%adstica.pdf>. Acesso em: $10 / 03 / 2018$.

ALVES, Rubem. A escola com que sempre sonhei sem imaginar que pudesse existir. Campinas: Editora Papirus, 2001.

BAUMAN, Zygmunt. 44 Cartas do mundo líquido moderno. Rio de Janeiro: Jorge Zahar Editor, 2011.

BRASIL, Ministério da Educação. Parâmetros Curriculares Nacionais para o Ensino Fundamental. Brasília, MEC/SEF, 1998.

BARROS, Eliana M. D. O gênero textual como articulador entre o ensino da língua e a cultura midiática. In: Gêneros textuais. Da didática das línguas aos objetos de ensino. São Carlos, 2009

BLANCHE-BENVENISTE, Claire. Estudios Linguísticos Sobre La Relación Entre Oralidad Y Escritura. GEDISA: Barcelona, 2009.
BLOOM, B. S. et al. Taxonomy of educational objectives. New York: David Mckay, 1956.

CALDEIRA, Ana Cristina Muscas. Avaliação da Aprendizagem em Meios Digitais: Novos Contextos. In: Congresso Internacional de Educação a Distância, 2004, Salvador-BA. Disponível em: <http://www.abed.org.br/congresso2004/por/htm/033TC-A4.htm>. Acesso em: 10/08/2020.

CANDIDO, Antonio. A literatura e a formação do homem. Ciência e cultura. São Paulo,v. 24, n. 9, p. 803-809, set. 1972.

CUNHA, Juliana Alves dos Santos Gaêta. Funções cognitivas e aprendizagem: a abordagem de Reuven Feuerstein. Estação Científica. Juíz de Fora,no 18, jul-dez/2017.

DOLZ, J. SCHNEUWLY, B. Gêneros orais e escritos na escola. Tradução e organização por Roxane Rojo e Glaís Sales Cordeiro. Campinas: Mercado das Letras, 2004.

FREIRE, Paulo. Pedagogia da Autonomia Saberes Necessários à Prática Educativa. Editora Paz e Terra: São Paulo,1996.

HODGES, Luciana Dantas. NOBRE, Alena Pimentel. Processos cognitivos, metacognitivos e metalingüísticos na aquisição da leitura e escrita. In: Revista Teoria e prática da Educação. V.15, n.3, p. 721. Set/dez2012.

MARCUSCHI, Luiz Antônio. Produção textual, análise de gêneros e compreensão. Parábola Editorial: São Paulo, 2008.

MORENO FERNÁNDEZ, Francisco. Qué español enseñar. Ed. Arco Libros: Madrid, 2000.

PACHECO, José. Escola da Ponte. Formação e transformação da educação. Petrópolis: Editora Vozes, 2008.

- Inovar é assumir um compromisso ético com a educação. Ed. Vozes: Petrópolis, RJ, 2019.

. Novas Histórias do Tempo da Velha Escola (CCIV). Brasília, 2020. Disponível em: <www.ecohabitare.com.br>. Acesso em 30/08/2020.

PACHECO, José. PACHECO, Maria de Fátima. Avaliação da aprendizagem na escola da Ponte. Editora Wak: Rio de Janeiro, 2012.

PROENÇA FILHO, Domício. A Linguagem Literária. Ed. Ática: Rio de Janeiro, 2006. 
Ministrar uma oficina remota em tempos de pandemia

VYGOTSKY, Lev Semenovich. A formação

social da mente. São Paulo: Martins Fontes, 1991.

ZOLETTI, Debora Ribeiro Lopes; PINTO, Maristela da Silva. Ministrar uma Oficina Remota em tempos de pandemia: uma experiência vivida por duas docentes humanistas dos cursos de Licenciatura em Letras da UFRRJ. Signo, Santa Cruz do Sul, v. 46, n. 85, p. 239-247, jan. 2021. ISSN 1982-2014. Disponível em: <https://online.unisc.br/seer/index.php/signo/article/view/15688>.

doi:https://doi.org/10.17058/signo.v46i85.15688. 